
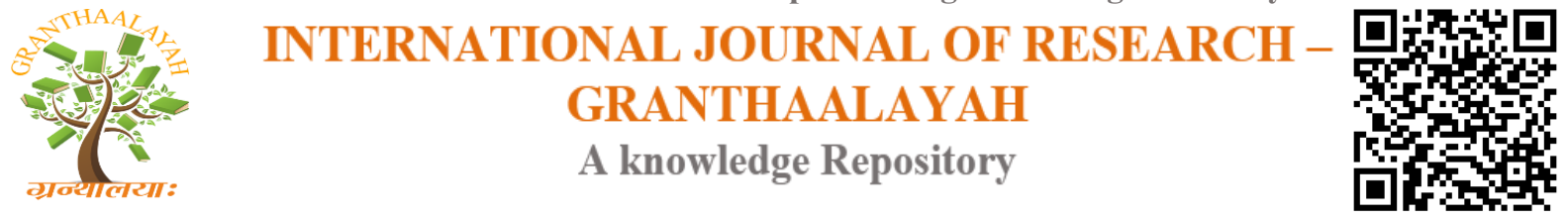

Science

\title{
ICT SOLUTION TO MINIMIZE ILLEGAL, UNREPORTED AND UNREGULATED (IUU) FISHING
}

\author{
Aruni Nisansala"1, Nihal Kodikara ${ }^{* 2}$, Chamath Keppitiyagama ${ }^{* 3}$, Damitha Sandaruwan ${ }^{* 4}$, \\ Kapila Dias $^{* 5}$, Ranjith Senadheera ${ }^{\# 6}$, Maheshya Weerasinghe ${ }^{* 7}$, Ishan Buddika ${ }^{* 8}$, Chamal \\ Lakshika $^{* 9}$, Nuwan Dammika ${ }^{* 10}$, Hasini Herath ${ }^{* 11}$, Nadun Liyanage ${ }^{* 12}$, Isura Nirmal ${ }^{* 13}$ \\ *University of Colombo School of Computing, Sri Lanka \\ \# LK Simulations (Pvt) Ltd, Sri Lanka
}

\begin{abstract}
Marine environment is one of the natural ecosystem which is been affected by the unscrupulous human activities. Lots of efforts are taken to preserve and maintain the balance of the aquatic resources by responsible bodies. European Union convention on the law of the sea has a great impact on avoiding the IUU fishing activities of the countries with large scaled fisheries industry. Fishing grounds should be harvested with caution otherwise whole could be endanger in extinction while harvesting the whole school of fish. There the fishermen are responsible for releasing under-weight fishes and the other fish types which are prohibited to be caught.

With the technology all the manual works has been eased and heightened in accuracy wise. Albeit the advantages are there, the main drawback is that they are being expensive. Localizing those products and requirement adding has been the major gap which has limited those commercial products being popularized in the countries with native languages. In this paper we have discussed a novel approach for fishing vessel tracking and catch reporting which minimizes above drawbacks.
\end{abstract}

Keywords:

IUU fishing, vessel tracking, localization, catch reporting.

Cite This Article: Aruni Nisansala, Nihal Kodikara, Chamath Keppitiyagama, Damitha Sandaruwan, Kapila Dias, Ranjith Senadheera, Maheshya Weerasinghe, Ishan Buddika, Chamal Lakshika, Nuwan Dammika, Hasini Herat, Nadun Liyanag, and Isura Nirmal, "ICT SOLUTION TO MINIMIZE ILLEGAL, UNREPORTED AND UNREGULATED (IUU) FISHING" International Journal of Research - Granthaalayah, Vol. 3, No. 10(2015): 117-127.

\section{INTRODUCTION}

Marine industry is one of the major contributors to the world economy. Billions of jobs are directly depend on the marine industry. Oceans are significant factor not only to the economy but to the food supply and the overall health and balance of the planet (Jayasinghe, Amarasinghe, \& Newton, 2015). Hence the perfect marine environment will ultimately provide invaluable ecosystem 
services to the humans, coastal as well as to all the sea creatures. Anthropogenic activities have always been the main reason in misbalancing these marine ecosystems. Primary living space of the all types of fishes is the oceans. As mentioned above the sustainability of the aquatic resources are directly and indirectly have a great impact on the human lives.

Due to the unscrupulous harvesting some varieties of fisheries the facing to the extinction and that have impact on the balancing of the marine environment. Fisheries scientists are under significant pressure as the status of the details on the fish stocks are unreliable and unavailable (Hutchings, 2012). With human activities the main risk has been on the fisheries food chain which could destroy the entire stability of the oceanic environment. And due to that many fishery species are facing to the extinction (Hutchings, 2012). Many responsible bodies have proposed constitutions with the aim of reducing the illegal human activities and conservation of the aquatic resources. Their effort of collecting data on the catching fisheries stock and avoid illegal harvesting has much effect on saving the fishery resource for tomorrow. Maritime affairs and fisheries wing of European Union is one of the active bodies which act again the illegal unreported and unregulated fishing activities. As the largest single market for fisheries products around the globe EU plays a significant role by implementing and maintaining the law of the sea (European Union, 2015). Union convention on the law of the sea that has most impact on setting up the exclusive economic zone (EEZ) is one other great effort which were taken back in 1982. This EEZ setting up has allocated the most lucrative fishing grounds under the jurisdiction of some coastal states (Kwadjosse, 2009). This has given the states to act against the illegal fishing activities.

EU maritime affairs and fisheries commission has alerted several countries on their fishing activities and has taken necessary banishment and legal reaction in order to decrease the IUU. In November, 2012 EU issued yellow cards to eight states due to their inability to combat against IUU fishing where the main weaknesses include shortcomings of an adequate and efficient vessel monitoring system, lack of deterrent sanctions for the high seas fleet, as well as lacking compliance with international and regional fisheries rules. This incident can be considered as one of the most recent active incident which EU taken responsibility to act against IUU (European Commision, 2015).

In order to reduce the IUU fishing activities different technical approaches are being introduced. Satellite based fishing vessel tracking is one common tactic used in commercial fishing activity monitoring and that approach has been accepted by the EU.

Based on the identified issues we have revealed the possibility of applying fishing vessel monitoring and catch reporting scheme based on the GPS location of the vessels. The modified version which includes features such as well-managed vessel monitoring system, which will reduce the illegal activities and rule violations, generate/maintain catch report and a fleet informer would be applying as vessel monitoring and catch reporting solution.

\section{BACKGROUND}

For the commercial ships AIS based tracking is the most recognized approach in vessel tracking. There are several well-known solutions provided by the commercial VTMS providers such as Transas (Transas, 2015), GeoVs (GeoVS Limited, 2015), Signalis (Signalis, 2015) etc. Siyara VTMS is one of the cost effective vessel tracking management system which comes in both 2D 
and 3D mode (Gunasekara C. , et al., 2013) (Gunasekara C. J., et al., 2012) based on AIS technology developed by the University of Colombo School of Computing (University of Colombo School of Computing, 2015). Siyara VTMS is focusing on tracking vessels but in a different context as the concept of VTMS is deployed based on AIS technology.

However the small fishing vessels are not privileged with the AIS facility as the large vessels. Hence surveillance them has to be done through satellite based system and generally it is an expensive method. Except vessel monitoring, fleet management and catch management facilities should be there to manage the fishing harvest. EU has complied relevant rules with each and every phase of this fishing activities in order to handle the IUU fishing. Hence the special feature of the fishing management applications is that they should include those extra features as well as tracking vessels.

The commercial products have been implemented in the international language, English and when it comes to the local markets each and every component should be localized properly. But when it consider the education background of the fisherman in countries such as Sri Lanka it is clear that they do not have a good educational background. Hence the complex user interfaces should be avoided from the system. To avoid this Siyara has used graphical interfaces with large images which convey a generic idea to the user/skipper. The user interfaces are localized and available in all three languages Sinhala, Tamil and English. This process can be adopted to any language and localized accordingly.

The special feature that it came through the survey is that the entire commercial product supports the fishing process from the fisherman's aspect but no proper data management from the ministry or authority level. Hence the proposed system has covered the entire network from the lowest level to the highest authority level by dividing system permissions to enter, edit and remove data.

There are several fishing vessel monitoring systems available in the commercial market (Visma, 2015) (CatchLog, 2015) (OLRAC , 2015). The fishing vessel monitoring concept is originated back in 1988 in Portugal and the reason was that the Portuguese authority noticed a huge degradation of the fish stocks as measured by volume of catches, size of individual species and research on available biomass (navigs, 2005). MONICAP was the first solution introduced by the Portuguese authority and it was very simple solution. But due to the technical issues and lack of resources they moved to remote tracking the fishing vessel and monitoring catch (fishing quotas) and effort(number of days at sea). With that the current version of VMS concept was born. Still after decades the reason behind the origin of the concept is same. Even today after taking that much effort, degrading live fisheries has been a great threat. Following this initiative motive many countries adopted the fishing vessel monitoring concept as a mandatory legal requirement in fishing industry (navigs, 2005).

VMS technology has benefited with the global satellite coverage as well as the GPS to accurately track the vessel positioning. Restriction on gear types, restriction on fishing time, quotes the fishing amount and restricting some areas for fishing are some other regulations which are been enforced by the authorizes in order to achieve sustainable fishing (Beke \& Bomeyer, 2014). Except the fishing vessel monitoring electronic catch data recording is one of the task which is introduced in order provide accurate and manageable details on fishing stocks. With this electronic catch reporting all the relevant parties would get the catching quotas in real time. 
Countries with a huge fisheries industry tend to enforce laws and force fishermen to use the VMS systems with the aim of preserving aquatic living stocks and managing it properly. Some of the quite popular commercial VMS solutions are contrast and compared with the Siyara VMS follows [12] (CatchLog, 2015) (OLRAC , 2015);

Table 1: Comparison between the VMS Solutions

\begin{tabular}{|c|c|c|c|c|}
\hline Feature & CatchLog & $\begin{array}{l}\text { Visma Fishery } \\
\text { Solutions }\end{array}$ & $\begin{array}{l}\text { Olrac Fishery } \\
\text { Solutions }\end{array}$ & $\begin{array}{l}\text { Siyara } \\
\text { eLogbook } \\
\text { Catch } \\
\text { Reporting } \\
\text { System } \\
\end{array}$ \\
\hline $\begin{array}{l}\text { Mode of data } \\
\text { exchange }\end{array}$ & $\begin{array}{l}\text { Real time data } \\
\text { exchange with } \\
\text { Satellite based } \\
\text { communication }\end{array}$ & $\begin{array}{l}\text { Real time data } \\
\text { exchange (once } \\
\text { in } 4 \text { hours) with } \\
\text { Satellite based } \\
\text { communication }\end{array}$ & $\begin{array}{l}\text { Real time data } \\
\text { exchange with } \\
\text { Satellite based } \\
\text { communication }\end{array}$ & $\begin{array}{lr}\begin{array}{l}\text { Offline } \\
\text { exchange }\end{array} & \text { data } \\
\text { wSith } \\
\text { GSM based } \\
\text { communication }\end{array}$ \\
\hline $\begin{array}{l}\text { eLogbook } \\
\text { Facility }\end{array}$ & Available & Available & Available & Available \\
\hline $\begin{array}{l}\text { Fleet } \\
\text { Management }\end{array}$ & Available & Available & Available & Available \\
\hline $\begin{array}{l}\text { Catch } \\
\text { Management }\end{array}$ & Available & Available & Available & Available \\
\hline $\begin{array}{l}\text { Crew } \\
\text { Management }\end{array}$ & Available & Available & Available & Available \\
\hline Cost & $\begin{array}{l}260 \$ \text { per vessel } \\
\text { per year }\end{array}$ & Not Available & Not Available & $\begin{array}{l}105 \$ \text { per vessel } \\
\text { per year }\end{array}$ \\
\hline $\begin{array}{l}\text { Language } \\
\text { Support }\end{array}$ & $\begin{array}{l}\text { English, Spanish } \\
\text { \& French. }\end{array}$ & English & $\begin{array}{l}\text { English (Can be } \\
\text { localized) }\end{array}$ & $\begin{array}{l}\text { Sinhala, Tamil, } \\
\text { English (Can be } \\
\text { localized) }\end{array}$ \\
\hline Platforms & $\begin{array}{l}\text { XP, Windows } 7 \\
\& 8\end{array}$ & Windows & Windows & $\begin{array}{l}\text { Windows } \\
\text { Android }\end{array}$ \\
\hline
\end{tabular}

\section{FISHING VESSEL COMMUNICATION IN SRI LANKAN CONTEXT}

Majority of the boats in the fishery harbor are IMUL (Inboard Multi-day Boats). Each of them is registered and must display the IMUL number assigned. Those boats are made of fiber glass and engines are locally transformed from motor vehicle and lorry engines as fishermen explained. Each boat should have a catch certificate issued by the ministry. IMUL boats are generally engage in fishing for 19-30 days. The preparation costs for a one journey exceeds LKR.100 000.

IMULs are equipped with the GPS locator and a marine radio system for communication with the Operations center. The operations center has a fixed marine radio and operational 24 hours of the day. The main problem lies with the communication equipment's in both control center and Boats. 
All the boats have same functional GPS locators from different vendors for getting the position of the boat in the middle of the ocean. Often this GPS coordinates are requested by the Operation Center and put that in the record book.

iCOM IC M 710 device is used as the marine radio device in the inspected fishing boat when we are at the Galle fishing harbor. The frequency ranges used are MF and HF frequencies. There is a predefined time in the day and each fisher boat must communicate with the operations center and update the status of the boat, crew, weather condition and their position. If the operations center is out of range, the boat calls to the nearest boat it can reach and relay the message.

Both of the equipment cost more than Rs 200000 and NOT available in the local market. Therefore, boat owners buy them from black market dealer paying them more than Rs 250000 . The equipment is then imported from Singapore and the antenna equipment is removed so that they can be easily cover from customs inspection. Therefore, without the original antenna, fisher men use the equipment with self-made antennas so that the equipment original performance will never be achieved moreover that can damage the equipment in long term.

Sailor 6302 equipment is fixed equipment installed in the operations center. It is basically a powerful radio transceiver covering more than more than $300 \mathrm{~km}$ radius. A radio operator at the operations center is taking the messages from the boats and records them in a record book (Boat ID, Time, Position and additional notes) 24 hours a day. Also communicate the weather conditions and fish diversity details in certain areas of the see. This equipment however provided by the Ministry. Currently, the officer explained that there is no method to mark the positions in a map. Therefore, border crossing and spatial awareness of the fishing boats are hard to understand by this method due to lack of real time chart plotting.

The project's aim is to consider the feasibility to introduce a new system for fishing boat tracking and monitoring. Thus the problem of buying GPS equipment and operating them will be reduced while increasing the cost affectivity. Although boat owners pay large amount of money, the purpose of the investment is not achieved $100 \%$. They have to say the coordinates via radio and the coordinates are written in a book.

There are several issues with the current methods. The people and drug smuggling cannot be stopped. There is no indication about crossing the boarders. Fishermen can easily turn the radio off and be unresponsive to the operation center. Also the power consumption of the current radio units is significant. Some of boats have solar panels installed but not all of them have that facility. Therefore, independent location transmitter is needed.

Foreign fishing vessels in the international seas use advanced satellite and sonar based technologies to identify the fish diverse areas. So they are taking the advantage of directly go to that area and harvest the fish. However, local fishers have to find those areas by themselves wasting more fuel and effort which can be used for actual fish harvesting. By plotting the locations of the boats in the sea to a map, the officers in the operations center can mark the fish diverse area and give the information to boats nearby. Also the weather information can be easily plotted in to the map. 
Each IMUL need to submit a log to the fishing harbor about their fish catch, types and amount of the fish catch, locations on the sea. However, the information collected are used for statistical purposes of the ministry and are not available for the fisher. They are collected in paper based manner. By using the information collected through the year, very important details can be harnessed including the fish diverse areas, patters, the relationships between sea currents and fish types etc.

\section{PROPOSED METHOD - ELECTRONIC LOGBOOK \& ELECTRONIC DATA VERIFICATION MODULE FOR FISHERY MANAGEMENT SUPPORT}

With the expertise on the marine related software solution providing, UCSC has proposed a low cost, accurate offline solution in tracking, monitoring and verification of fishing activities. This framework has several components and interfaces which are given to the stakeholders granting permission according to their levels. In native process there are several parties. Those parties can be listed below with their responsibilities as follows.

Table 2: System Interface Assignment

\begin{tabular}{|c|c|c|}
\hline Stakeholder & Responsibilities & System Interface \\
\hline \multirow[t]{2}{*}{ Ship Owner } & Licensing ships & Web interface \\
\hline & Manage ship crew & \\
\hline \multirow[t]{3}{*}{ Skipper } & Check crew & Android mobile interface \\
\hline & Check fishing gears & \\
\hline & Enter catch details & \\
\hline \multirow[t]{4}{*}{ Fisheries Inspector (FI) } & Verify fishing crew & Android mobile interface \\
\hline & Verify fishing gears & \\
\hline & Verify entered catch details & \\
\hline & Report illegal activities & \\
\hline \multirow{2}{*}{$\begin{array}{l}\text { Law enforcement at the } \\
\text { harbor }\end{array}$} & Revalidate the crew & Android mobile interface \\
\hline & Revalidate the fishing gears & \\
\hline \multirow{2}{*}{$\begin{array}{l}\text { Quality Control } \\
(Q C)\end{array}$} & $\begin{array}{l}\text { Validate the fishing route } \\
\text { Validate the catch information }\end{array}$ & $\begin{array}{l}\text { Standalone } \\
\text { interface }\end{array}$ \\
\hline & Issuing the catch certificate & $\begin{array}{l}\text { \& Web interface with } \\
\text { different permission levels }\end{array}$ \\
\hline Exporter & $\begin{array}{l}\text { Check the ship route } \\
\text { Place orders in order to purchase } \\
\text { fishing stocks } \\
\text { Apply for catch certificate }\end{array}$ & Web interface \\
\hline
\end{tabular}

The system includes three types of user interfaces; web, mobile and standalone system. Each module is connected to the central database. The GPS enabled mobile interface is given to the skipper replacing the traditional paper work on the catch entering. The data collection will be done offline and the data transferring to the central data location will be done as soon as the vessel enters to the GSM range. This data transferring is depicted in the Figure 1.

As soon as the data are retrieved by the central database ship owners, FI and QC unit could view data and verify the voyage. This process has reduced number of labor hours which needs to verify 
one voyage and all the paper work. The process has also heightened the transparency of the process as the details could be viewed and monitored accordingly.

Data input for one voyage could be summarized as follows in Figure 2. This data processing procedure could be generalized and task could be assigned to different levels. Basically the system has covered all the stakeholders and has provided them the required details for their authority level. However the removing or adding responsible bodies can be done easily with the system. The interfaces are designed in order to heighten the user interaction. There are three types of interfaces designed.

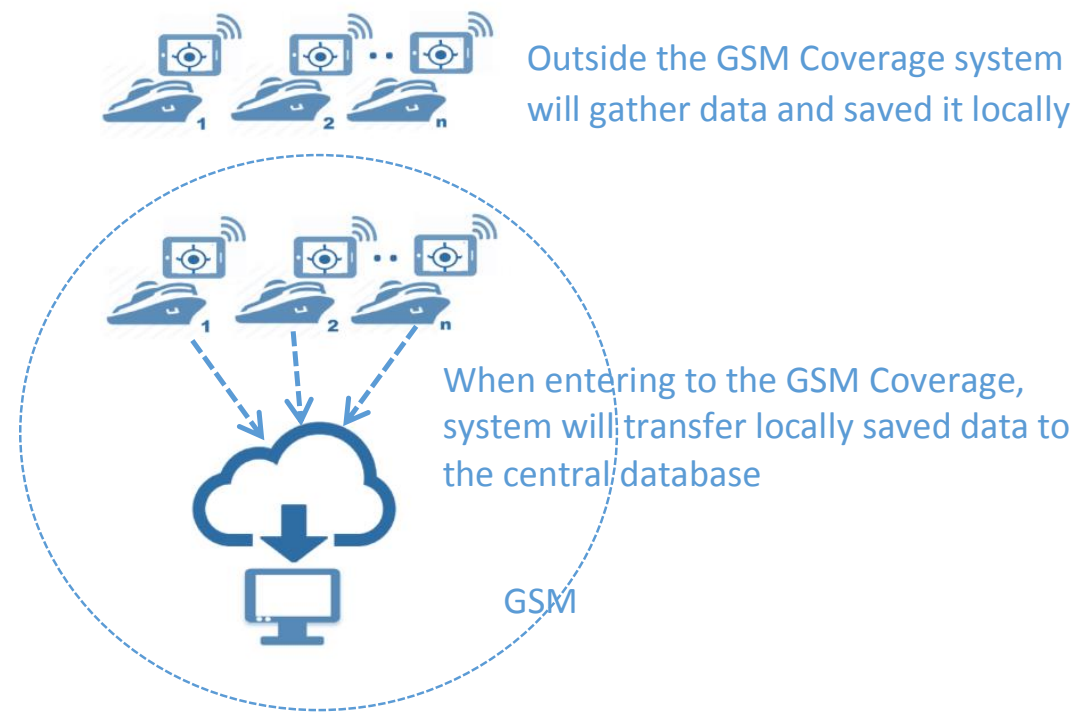

Figure 1: Data transferring between fishing vessels and the central

@Departure

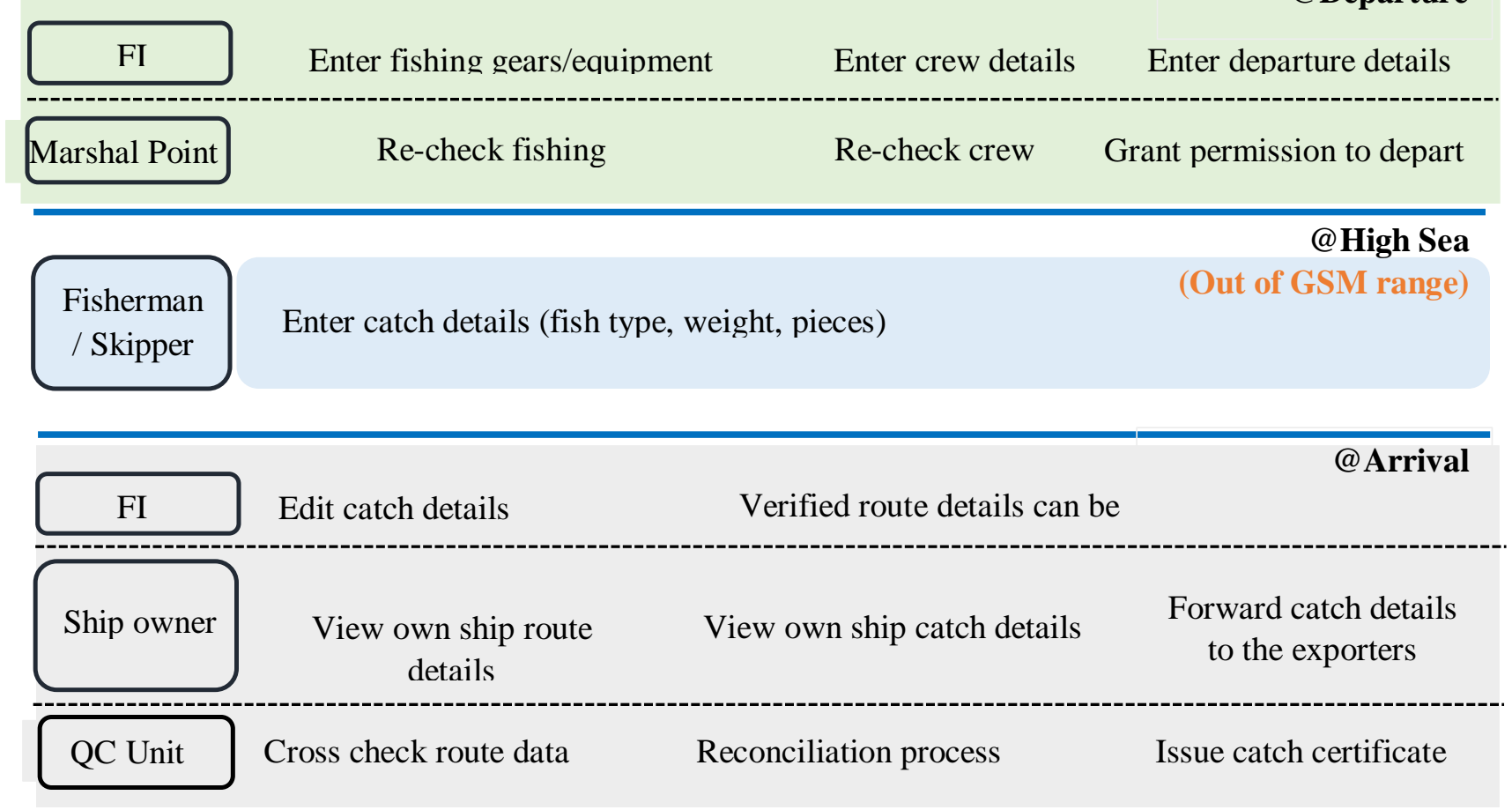

Figure 2: Data input to the system in single voyage 


\subsection{MOBILE INTERFACE FOR FISHERMEN/SKIPPERS}

Fishermen application is confined simple using a graphical iconic interface. This has eased the usage of the application. When it consider the education background of those people it was clear that they did not have a literacy level. Since the iconic interface has a great impact which has motivated users to use it.

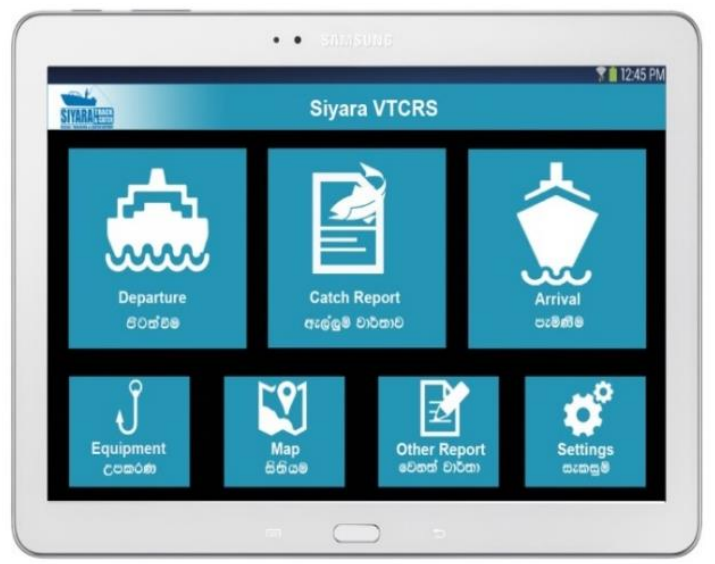

(a)

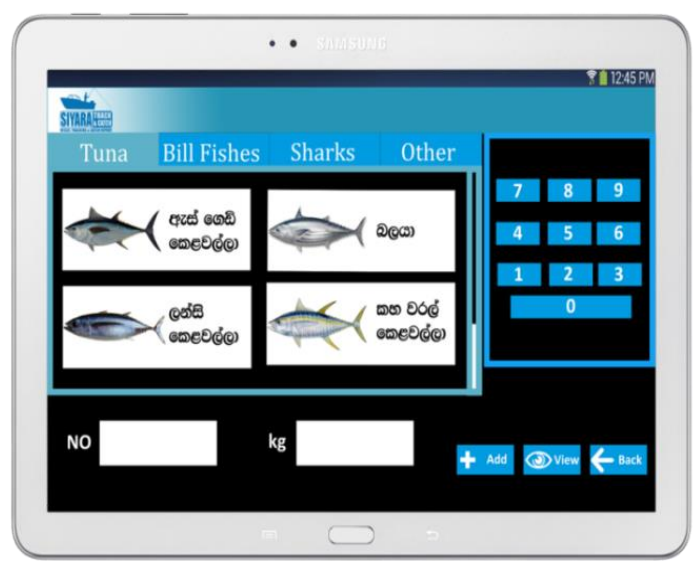

(b)

Figure 3: (a) Home interface of Siyara Vessel Tracking and Catch Reporting System (b) Catch Report interface of Siyara Vessel Tracking and Catch Reporting System

Fisheries inspector and the other law enforcement officers are given a mobile interface as they have to verify the information quickly. Those applications are also kept simple with more iconic interfaces to heighten the user interaction.

Geo-offence alarm system is also included in the mobile view to warn the fishermen about the illegal border crossings. With this feature the awareness of border crossing is heightened and this will directly reported to the other higher levels to take necessary legal actions.

\subsection{WEB INTERFACE}

Once the data is retrieved the web interface will allow seeing the actual voyage and catching location details. The entire catch quota with species and the vessel route details will be available to analyze compare and prepare reports. As the historical data is saved they can view any route between any dates and retrieve information about ship voyage or catch. This graphical notation will relaxed the catch verification process. The possible ship locations are marked in circles considering their speed and time. Due to the high cost commercial solutions have confined data emitting to per hours. But with Siyara the data will be gathered within 10minutes gap. This will give the real path with more details which will ensure the vessel path in more realistic manner than commercial systems. 
The owners will be getting access only to their own ship/ships. He will also grant privileges to view his ship route and catch details. Law officers and anyone with permission can also be given this web interface to view any voyage.

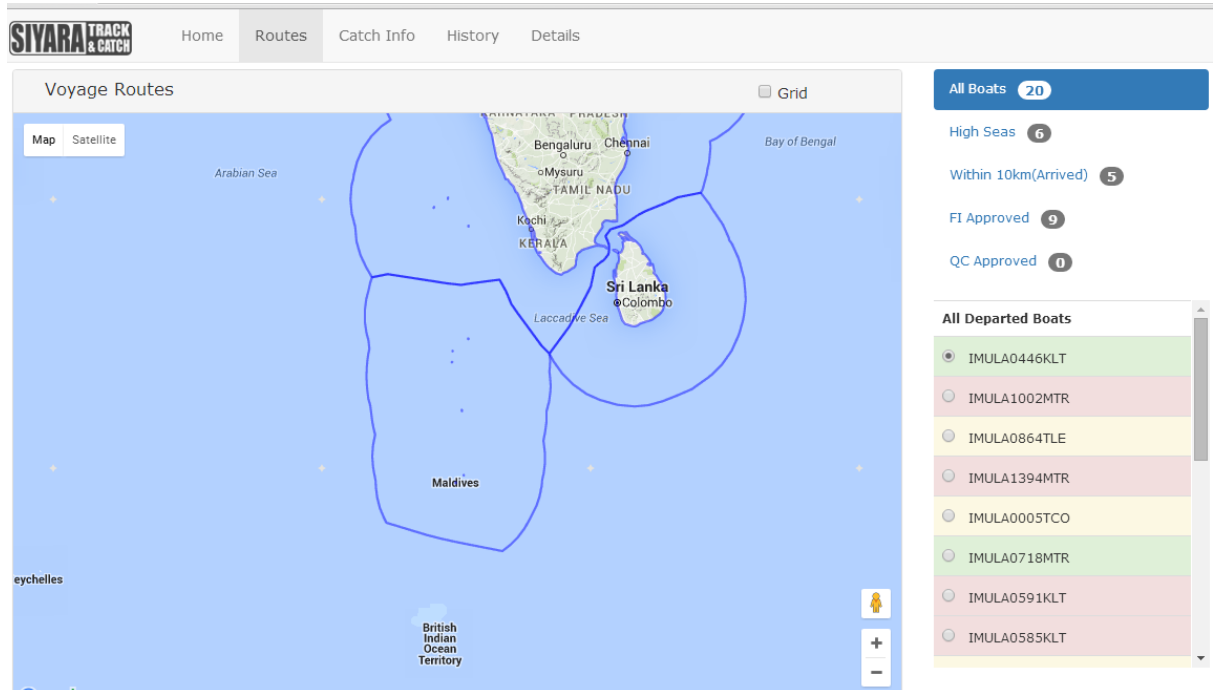

Figure 4: Instance of web interface

\subsection{QC VERIFICATION MODULE}

All the details are verified and reported in the quality control units. Here authorized person will be monitoring the vessel route and all the catch details and verified the voyage. If the voyage has any illegal activity such as fishing in restricted areas, using any illegal fishing gears then the voyage will be labeled as IUU and alerts will be given to the ship owners and exporters. Otherwise officer could verified the process and issue the catch certificates and other relevant documents.

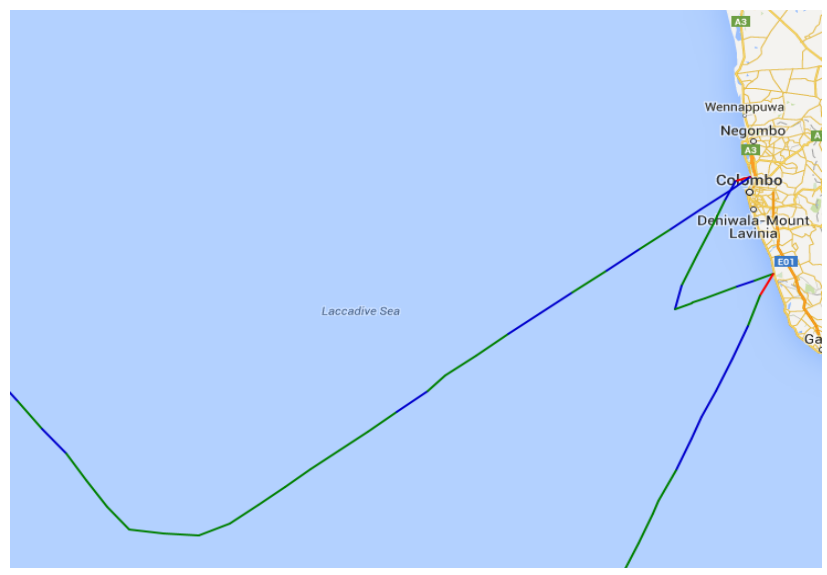

(a)

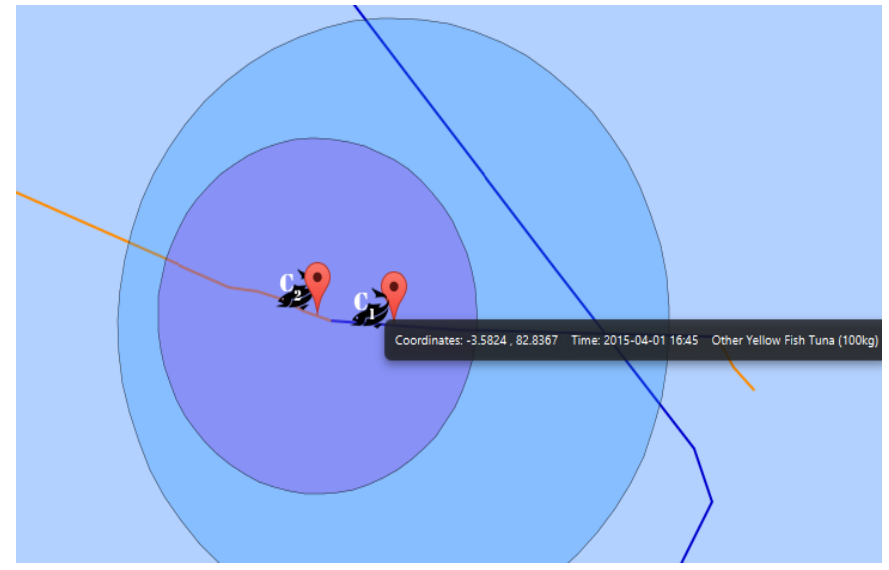

(b)

Figure 5: (a) Track details of particular vessel. (b) Catch details of particular vessel 


\section{CONCLUSIONS AND FUTURE WORK}

Fisheries industry has been major source of food supply for human and a provider of employment enriching the economy. Although the aquatic resources are renewable it is not infinite and needed to be managed properly in order to prevail the sustainability and eco balance. Hence preventing IUU fishing activities is a timely requirement.

Siyara is a low cost, affordable and localizable solution to all. It well addresses the cost gap replacing the satellite communication with the GSM coverage data communication. Simple and iconic graphical interfaces have heightened the user interaction while the commercial solutions offer very complex and textual interfacing. Based on the literacy level of each user, modules are well organized, designed and presented with Siyara. Localized with all three language has also given a positive feeling to the user. As the product could be localized to any country the countries with low economy or the developing countries in Asia-Pacific regions could be benefited with this solution. Managing data properly with reporting module has also added extra value to the solution. All the report is customizable and both graphical and textual formats are available.

Some of the extendable features and knowledge which could be gathered from the proposed systems are;

- Extract knowledge on rich fishing grounds, less productive zone, productivity vs. time of the year and generate reports to analyze those data for management decision making

- Identifying abnormal behaviors (divert from the route, suspicious behaviors) using gathered data pool.

After the initial deployment the solution should be enhanced iteratively based on the feedbacks of all the stakeholders.

\section{REFERENCES}

[1] R.P. Prabath K. Jayasinghe, Upali S. Amarasinghe, and Alice Newton, "Evaluation of marine subareas of Europe using life history parameters and trophic levels of selected fish populations," Marine Environmental Research, 2015.

[2] Jeffrey a.,Myers, Ransom a.,García, Veronica B.,Lucifora, Luis O., Kuparinen, Anna Hutchings, "Life-history correlates of extinction risk and recovery potential," Ecological Applications, vol. 22, no. 4, pp. 1061-1067, 2012.

[3] European Union. (2015, September) European Commision - Fishing outside EU. [Online]. http://ec.europa.eu/fisheries/cfp/international/index_en.htm

[4] Theodore Kwadjosse, "the Law of the Sea: Impacts on the Conservation and Management of Fisheries Resources of Developing Coastal States - the Ghana Case Study," 2009.

[5] European Commision. (2015, October) European Commision Press Release Database. [Online]. http://europa.eu/rapid/press-release_IP-14-1132_en.htm

[6] Transas. (2015, October) Transas 3DVTMS. [Online]. http://www.transas.com/products/3DVTS

[7] GeoVS Limited. (2015, October) GeoVS Limited. [Online]. http://vimeo.com/geovs Signalis. (2015, October)

[8] Signalis - Vessel Traffic Services. [Online]. http://www. signalis.com/styris/styrisR-vts/ 
[9] Sandaruwan, D., Kodikara, N., Keppitiyagama, C., Samarasinghe, P., Perera, C., Dias K., Ranjith A., Ranjith S., Dilhari A., Randika A., Poshita D., ArunikaS., Damith L., Realtime 3D Vessel Traffic Monitoring System for Commercial Ports (3DVTMS), SEARCC International Conference 2013, Colombo. ISSN 2279-3895

[10] Gunasekara, C., Uduwarage, C,. Keppetiyagama, C., Kodikara, N.. Sandaruwan, D., Senadheera, R,. and Gunaseela J. (2012) Low Cost 3D Immersive Telepresence For Survaillance, Planning, Maneuring : 3D-COP. Computer Games Multimedia and Allied Technology 2012 (CGAT 2012) Thailand, ISSN: 2251-1679.page 12-16

[11] University of Colombo School of Computing. (2015, October) Siyara Harbour VTMS. [Online]. http://www.siyara.org/

[12] Visma. (2015, October) Visma Consulting. [Online]. http://www.fisherysolution.com/

[13] CatchLog. (2015, October) CatchLog. [Online]. http://www.catchlog.com/

[14] OLRAC. (2015, October) OLRAC SPS. [Online]. http://www.olsps.com/

[15] Robert navigs, "Fishing Vessel Monitoring Systems : Past, Present and Future," The High Seas Task Force, Paris, 2005.

[16] Mike Beke and Roland Bomeyer, "Illegal, Unreported and Unregulated Fishing: Sanctions in the EU," Study IP/B?PECH/IC/2013-184, 2014. 